\title{
Produção e conservação in vitro de plantas medicinais: introdução da biotecnologia vegetal no ensino médio
}

\author{
Production and in vitro conservation of medicinal plants: introduction of plant biotechnology in \\ high school
}

Autores

Rachel Fatima Gagliardi. Professora adjunta. Universidade do Estado do Rio de Janeiro, Núcleo de Biotecnologia Vegetal/IBRAG

E-mail: gagliard@uerj.br

Claudia Ribeiro da Silva. Bióloga. Universidade do Estado do Rio de Janeiro, Departamento de Biofísica e Biometria/IBRAG.

E-mail: crsilva@uerj.br

Bianka de Oliveira Soares. Bióloga. Universidade do Estado do Rio de Janeiro, Núcleo de Biotecnologia Vegetal/IBRAG.

E-mail: biabiouerj@yahoo.com.br

Renata Garcia. Bióloga. Universidade do Estado do Rio de Janeiro, Núcleo de Biotecnologia Vegetal/IBRAG.

E-mail: renatagarci@gmail.com

Jamine de Almeida Pettinelli. Doutoranda. Universidade do Estado do Rio de Janeiro, Núcleo de Biotecnologia Vegetal/IBRAG.

E-mail: jamine188@yahoo.com.br

Isabela Brandão de Sousa. Doutoranda. Universidade do Estado do Rio de Janeiro, Núcleo de Biotecnologia Vegetal/IBRAG.

E-mail:belabiouerj@gmail.com

Recebido em: 12/08/2016 Aprovado em: 16/01/2018

DOl: 10.12957/interag.2017.25079

\section{Artigo}

Com base na importância da biodiversidade vegetal enquanto recursos genéticos aplicáveis à farmacologia e outras áreas econômicas, os métodos biotecnológicos de produção e conservação de plantas constituem importantes ferramentas para garantir o desenvolvimento sustentável. O objetivo deste trabalho foi apresentar a Cultura de Tecidos Vegetais como importante ferramenta biotecnológica, com aplicação na conservação de recursos genéticos, estimulando a discussão nas escolas públicas de Ensino Médio, acerca do desenvolvimento sustentável. Para isso, foram estabelecidas

\section{Abstract}

Based on the importance of plant biodiversity as genetic resources applicable to pharmacology and other economic areas, biotechnological methods of plant production and conservation are important tools to ensure sustainable development. The objective of this work was to present the Plant Tissue Culture as an important biotechnological tool, with application in the conservation of genetic resources, stimulating the discussion in public high schools about sustainable development. In order to achieve this, goals were established in order to strengthen relations between the university and schools, offering 
metas visando estreitar relações entre a universidade e as escolas, oferecendo alternativas didáticas para o ensino público, além de divulgar as oportunidades de trabalho no âmbito da Biotecnologia Vegetal. Após uma avaliação preliminar com o 9a ano do nível fundamental da Escola Municipal Argentina, o projeto foi aplicado às turmas do $3 \circ$ ano do nível médio do Colégio Estadual João Alfredo e a metodologia qualitativa e quantitativa, constituiu-se de palestras e documentários apresentados por estudantes de graduação e pós-graduação. Além disso, os alunos participantes do projeto acompanharam a rotina de cultura de tecidos vegetais nos laboratórios do Núcleo de Biotecnologia Vegetal da UERJ. A avaliação do impacto tem sido baseada na frequência às atividades e na comparação das respostas dos alunos a um questionário estruturado, sobre conhecimentos básicos e aplicados, direcionados à Biotecnologia Vegetal, respondido antes e ao final do projeto. Este trabalho reporta os principais resultados obtidos entre 2013 e 2015 e nestes três anos de avaliação, observou-se que, apesar da dificuldade de aprofundamento, em razão de uma deficiência crônica em biologia e fisiologia vegetal, observa-se uma aceitação rápida dos novos conceitos introduzidos. As razões para este fenômeno e as estratégias para contornar as dificuldades são discutidas neste artigo.

Palavras-chave: Desenvolvimento sustentável; Cultura de tecidos vegetais; Ensino de Biologia; Conservação in vitro.

Área temática: Tecnologia e Produção / Educação

Linha de extensão: Temas específicos / Desenvolvimento humano didactic alternatives for public education, as well as disseminating opportunities for work in the field of Plant Biotechnology. After a preliminary evaluation with the 9th grade level of the Argentine Municipal School, the project was applied to the 3rd year classes of the middle level of the João Alfredo State College and the qualitative and quantitative methodology consisted of lectures and documentaries presented by students undergraduate and postgraduate courses. In addition, students participating in the project followed the routine of plant tissue culture in the laboratories of the Plant Biotechnology Center of UERJ. The impact assessment has been based on the frequency of activities and the comparison of the students' answers to a structured questionnaire about basic and applied knowledge, directed to Plant Biotechnology, answered before and at the end of the project. This work reports the main results obtained between 2013 and 2015 and in these three years of evaluation, it was observed that, despite the difficulty of deepening, due to a chronic deficiency in biology and plant physiology, a rapid acceptance of the new concepts introduced. The reasons for this phenomenon and the strategies to overcome the difficulties are discussed in this article.

Keywords: Sustainable development; Plant tissue culture; Biology teaching; in vitro preservation. 


\section{Introdução}

A biotecnologia Vegetal é uma importante ferramenta para o desenvolvimento de processos e produtos de interesse, utilizando-se plantas como matérias-primas. Os benefícios da aplicação da biotecnologia estão diretamente relacionados com o desenvolvimento sustentável, refletindo no aumento da produção de alimentos, medicamentos, combustíveis e outros produtos, interferindo na política econômica do País.'

A biotecnologia moderna, advinda dos novos conhecimentos gerados na biologia molecular, tem sido motivo de debates por conta do grande impacto social causado no momento atual, em função do potencial para alterar a natureza. Assim, os conhecimentos em biologia devem subsidiar o julgamento crítico de questões polêmicas, como considerado nos PCNs para o Ensino Médio. ${ }^{2}$ Dentre os princípios que orientam o Ensino Médio, a conclusão do processo formativo da Educação Básica depende da compreensão dos fundamentos científicos e tecnológicos presentes na sociedade contemporânea, relacionando a teoria com a prática. ${ }^{3}$

Nos últimos anos, como relatado em outras instituições ${ }^{4,5,6}$, os alunos ingressantes no Curso de Ciências Biológicas da Universidade do Estado do Rio de Janeiro (UERJ) não demonstram o interesse esperado na área de Biologia Vegetal, apesar da atualidade da matéria, fundamental para compreensão dos desequilíbrios ambientais observados atualmente. Embora as razões para explicar este fato não sejam muito claras, o desinteresse por parte dos alunos é um fenômeno de causa multifatorial, passando por aspectos sociais, econômicos e culturais, pela formação dos professores, e pela distribuição desigual do conteúdo entre as séries ${ }^{7,8}$. Além disso, quando presente, o ensino de Biologia vegetal é, geralmente, calcado em descrições anatômicas voltadas à classificação, com nomenclatura incompreensível, e sem apoio de aulas práticas, na maioria das escolas.,10

O fato é que os alunos que chegam à Universidade carecem de conhecimentos básicos sobre a biologia e a fisiologia vegetal, o que dificulta a compreensão e o posicionamento ativo em projetos de conservação.

Visando contribuir para reverter essa situação, este projeto abre um espaço aos alunos de graduação e pós-graduação em Biologia, para exercitarem a comunicação e a análise crítica de conceitos importantes dentro do tema Biotecnologia aplicada à Conservação de Recursos Vegetais, principalmente aqueles com potencial terapêutico.

Assim, o projeto, através de suas atividades e discussões também pode contribuir na formação de opinião ${ }^{11}$ embasada cientificamente, acerca da necessidade de conservação da biodiversidade vegetal. A temática do projeto é adequada à 3 a série do ensino médio, na medida em que visa fomentar nos estudantes a consciência do real valor dos recursos naturais, embasando uma postura responsável em relação aos problemas ambientais atuais, com o propósito de buscar soluções sustentáveis para o desenvolvimento econômico futuro. ${ }^{12}$

Dentre as muitas formas de conservar a biodiversidade, a Biotecnologia Vegetal, através da cultura de tecidos vegetais permite a manipulação de plantas e possibilita a obtenção produtos de interesse, com aplicações na agricultura e na indústria farma- 
cêutica. Nesta proposta, as plantas medicinais utilizadas em trabalhos acadêmicos na UERJ são usadas como modelo de espécies de interesse econômico, em função de seu potencial farmacológico e da estreita ligação cultural com os seres humanos desde tempos imemoriais.

\section{Objetivos e Metas}

Este projeto apresenta o objetivo geral de apresentar a Cultura de Tecidos Vegetais como importante ferramenta biotecnológica, com aplicação na conservação de recursos genéticos, estimulando a discussão de forma contextualizada nas escolas públicas de Ensino Médio, acerca do desenvolvimento sustentável, importante tema dentro das ciências da atualidade. Para isso, a produção de plantas in vitro de espécies medicinais foi apresentada em todas as suas etapas. Além disso, foram traçadas como metas extensionistas: (i) Estreitar relações entre a universidade e as escolas; (ii) Envolver os estudantes de graduação e pós-graduação no ensino de Biotecnologia Vegetal; (iii) Oferecer alternativas didáticas para o ensino de biologia da escola pública; (iv) Estimular o público-alvo e informar sobre as oportunidades de trabalho no âmbito da Biotecnologia Vegetal.

\section{Metodologia}

\section{Público-alvo}

O projeto foi inicialmente aplicado na Escola Municipal Argentina em 2012 e, de 2013 a 2015, no Colégio Estadual João Alfredo (CEJA), ambos localizados no bairro de Vila Isabel, Zona Norte do RJ, nas proximidades da UERJ, dispensando a necessidade de recursos para transporte. Em relação ao ensino médio, dependendo do ano, participaram quatro ou cinco turmas de 3ano, do turno da manhã, com cerca de 40-50 alunos cada, perfazendo um total de 560 alunos contemplados, ao final de três anos.

A avaliação do projeto se baseou em métodos qualitativo e quantitativo, com uso de questionário estruturado cuja análise detalhada das questões e temas abordados pode ser acessada em trabalho anterior do grupo ${ }^{13}$. Foram respeitados os códigos de ética, ${ }_{1}^{14}$ resguardando-se o direito ao sigilo quanto à identificação dos alunos, assim como à confidencialidade das informações individuais geradas. Este trabalho é parte do projeto "Produção e conservação in vitro de plantas medicinais" cadastrado desde 2012 no Departamento de Extensão da Universidade do Estado do Rio de Janeiro (DEPEXT no 4328) e na SEEDUC (Proc E 03/015/1494/16).

\section{Palestras}

Três palestras de nível introdutório foram apresentadas na própria escola, por alunos do curso de graduação em Ciências Biológicas e por alunos do Programa de Pós-graduação em Biologia Vegetal da Universidade do Estado do Rio de Janeiro (UERJ), para todas as turmas participantes. As palestras incluíram, primeiramente, temas básicos sobre 
biologia vegetal, tais como: divisão celular, replicação de DNA e fotossíntese, fundamentais para a compreensão da produção biotecnológica de plantas. Na sequência, foi ministrada uma palestra sobre a cultura de tecidos vegetais e suas aplicações econômicas e ecológicas, com destaque para a produção de espécies medicinais selecionadas dentre as pesquisas do Núcleo de Biotecnologia Vegetal e do Programa de Pós-graduação em Biologia Vegetal da UERJ.

\section{Filmes-documentários}

Foram selecionados dois documentários, dentre os materiais disponíveis em vídeo, produzidos ou dublados em língua Portuguesa: (i) "A vida secreta das plantas", abordando aspectos importantes da biologia e da fisiologia vegetal, produzido pela British Broadcasting Corporation (BBC), e (ii) "Benefícios da Biotecnologia na Agricultura", sobre a aplicação de métodos biotecnológicos visando o melhor aproveitamento de plantas pelo Homem, produzido pela Empresa Brasileira de Pesquisa Agropecuária (Embrapa). Ambos os documentários foram apresentados na própria escola e após as atividades foram promovidas discussões sobre o uso da Biotecnologia para conservar recursos genéticos e auxiliar o desenvolvimento sustentável, com ênfase nos exemplos apresentados nos documentários.

\section{Visita técnica}

Dez alunos de cada turma foram selecionados em função dos melhores rendimentos nos questionários e, foram acompanhados durante uma visita técnica aos laboratórios do Núcleo de Biotecnologia Vegetal do Instituto de Biologia Roberto Alcantara Gomes, UERJ, por estagiários membros da equipe. Durante a visita foram apresentadas todas as etapas da produção de plantas medicinais in vitro, desde a descontaminação de matrizes até a aclimatização dos clones produzidos na cultura de tecidos vegetais. Ao final, cada aluno recebeu uma muda in vitro de espécie nativa com potencial medicinal, com instruções para a transferência para o ambiente ex vitro.

\section{Análise de dados}

O impacto causado nos alunos participantes do projeto tem sido avaliado com base no rendimento em um questionário diagnóstico, além do parâmetro de frequência. $O$ questionário, aplicado antes e ao final do projeto, continha 10 questões de múltipla-escolha com uma única resposta certa, abordando os temas de biologia básica (questões 1 a 5 ) e biotecnologia vegetal ( 6 a 10). O rendimento individual foi definido pela comparação entre as notas obtidas pelos alunos antes e ao final do projeto. $O$ desempenho dos estudantes, considerando os diferentes anos de aplicação, foi definido pelo percentual de alunos em cada turma que acertaram as questões de conhecimento básico e aplicado e o rendimento foi a diferença entre as notas antes e o depois da aplicação do projeto. O rendimento das turmas consistiu na média do percentual de acertos dos alunos nos questionários inicial e final, por turma. Foi avaliado ainda o rendimento total, calculado como a média do rendimento das turmas por ano de projeto. 
A avaliação qualitativa do impacto do projeto foi realizada através de uma questão discursiva sobe a importância das plantas para o futuro da humanidade onde o posicionamento dos alunos foi dividido em categorias extraídas das próprias respostas. Além disso, as impressões dos estudantes que participaram da equipe executora foram discutidas e analisadas criticamente ao final de cada ano, com a sugestão de modificações e adequações para o ano seguinte, registradas através de relatório anual ao Departamento de Extensão da Universidade.

\section{Resultados e Discussão}

Inicialmente, foi realizada uma avaliação preliminar com alunos do nono ano do ensino fundamental, da Escola Municipal "República Argentina". Entretanto, os resultados, obtidos no questionário diagnóstico, demonstraram grande dificuldade dos alunos para fixar conceitos que dependiam de um embasamento em biologia vegetal, ainda não concretizado até o nono ano. Por esta razão, para dar continuidade à proposta, o nível escolar do público- alvo foi alterado para o nível médio, como descrito na metodologia. A partir de então, a avaliação em forma de questionário, aplicado antes da realização das atividades e ao final do projeto, demonstrou a compreensão dos novos conceitos introduzidos, mas enfatizou uma deficiência nos conceitos básicos de Biologia Vegetal, indicando a necessidade de um reforço dos temas trabalhados na escola para integrar o conhecimento básico aos conteúdos novos da Biotecnologia Vegetal.

Após a apresentação dos documentários, foram promovidas discussões sobre o uso da Biotecnologia de forma contextualizada, dentre as ciências da atualidade, como a Educação Ambiental, a Conservação de Recursos Genéticos e a Agronomia. Foi possível também desmistificar os avanços científicos em Biotecnologia Vegetal, apresentando suas aplicações e implicações. A última etapa do projeto tem sido a visita técnica aos laboratórios do Núcleo de Biotecnologia Vegetal da UERJ, oferecida aos alunos de cada turma com melhor desempenho representado pela frequência e rendimento nos questionários. Nos laboratórios acompanharam as atividades práticas realizadas rotineiramente e receberam mudas de uma espécie medicinal produzida in vitro, com instruções para a sua manutenção e aclimatização. Esta etapa é crucial para dar a dimensão concreta da aplicabilidade do método. O projeto tem apresentado resultados relevantes, uma vez que os alunos têm apresentado melhoria geral no desempenho, indicando a aquisição de conhecimentos relacionados à 3a série (Gráfico 1).

Além disso, durante as atividades, os alunos participantes foram informados sobre alternativas biotecnológicas de conservação e novas oportunidades profissionais nesta área. Embora o interesse não tenha sido o mesmo para todos os alunos, boa parte tem demonstrado claramente uma mudança de comportamento ao compreender a proposta e os conceitos novos sobre o tema. Possivelmente, porque temas tratados por ações públicas e/ou pela mídia estejam mais próximos da realidade dos alunos. ${ }^{15}$

Ao longo dos últimos quatro anos, a abrangência passou de 80 alunos do ensino fundamental em 2012 (dado não incluído na análise do triênio), para 228 alunos contemplados 
no ensino médio em 2015, atingindo mais que o dobro do número de alunos (Tabela 1).

Tabela 1. Percentual de participação de alunos a cada ano de projeto

\begin{tabular}{ccccccc}
\hline \multirow{2}{*}{$\begin{array}{c}\text { Total de } \\
\text { alunos }\end{array}$} & \multicolumn{6}{c}{ Participação no projeto } \\
\cline { 2 - 7 } & \multicolumn{3}{c}{160} & \multicolumn{2}{c}{2014} & \multicolumn{2}{c}{2015} \\
\cline { 2 - 7 } Etapas & \multicolumn{5}{c}{ Frequência às atividades } \\
\cline { 2 - 7 } & Total & $\%$ & Total & $\%$ & Total & $\%$ \\
\hline Inicial & 115 & 64 & 150 & 75 & 169 & 74 \\
Final & 129 & 72 & 138 & 69 & 144 & 63 \\
Todas & 115 & 64 & 128 & 64 & 130 & 57 \\
\hline
\end{tabular}

A apresentação fundamentada de uma nova tecnologia, aos alunos do ensino público através de um trabalho direcionado, em função das dificuldades específicas desse público-alvo, representa um desafio até para os professores experientes, situação fácil

A apresentação fundamentada de uma nova tecnologia, aos alunos do ensino público através de um trabalho direcionado, em função das dificuldades específicas desse público-alvo, representa um desafio até para os professores experientes, situação fácil de ser comprovada entre esses profissionais. Os resultados deste projeto ao longo dos últimos anos demonstram que é possível introduzir novos conhecimentos sobre temas atuais, o que motiva e desperta a curiosidade necessária ao aprofundamento de cada aluno. Entretanto, esses conhecimentos precisam ser integrados a uma base conceitual mais sólida. Durante a aplicação do projeto, este reforço pode ser obtido através de um planejamento conjunto com a professora responsável pelas turmas contempladas.

De 560 alunos do ensino médio contemplados nos três últimos anos, 373 participaram de todas as atividades do projeto. Embora se observe uma variação na adesão, o percentual de alunos que participam de todas as etapas e concluem com o questionário ao final, permanece estável há três anos, em torno de 60 a 70\% do total de alunos por ano (Tabela 1). O rendimento com base no questionário diagnóstico também não apresentou diferença entre os três anos de projeto (Gráfico 1). 
Gráfico 1. Avaliação do rendimento das turmas por ano de projeto

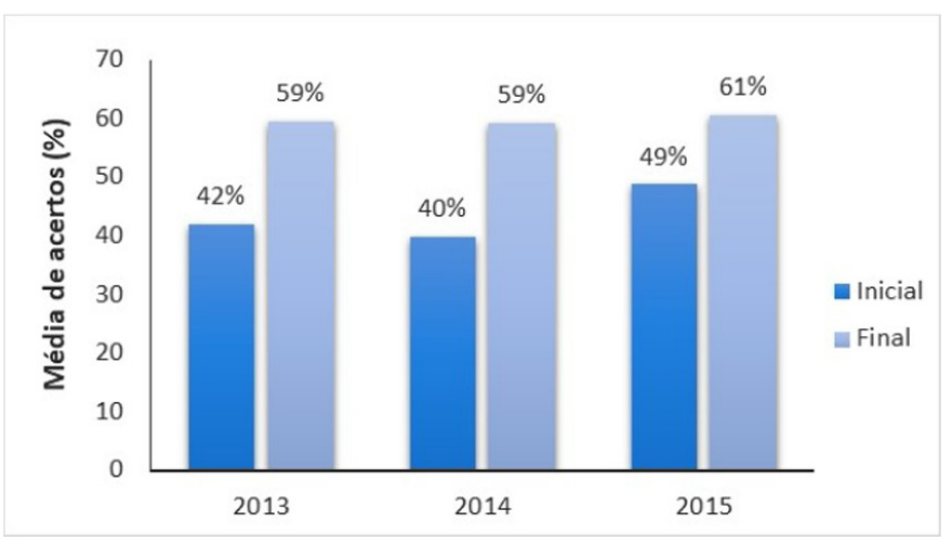

Gráfico 2. Avaliação do rendimento total em Biologia Vegetal básica

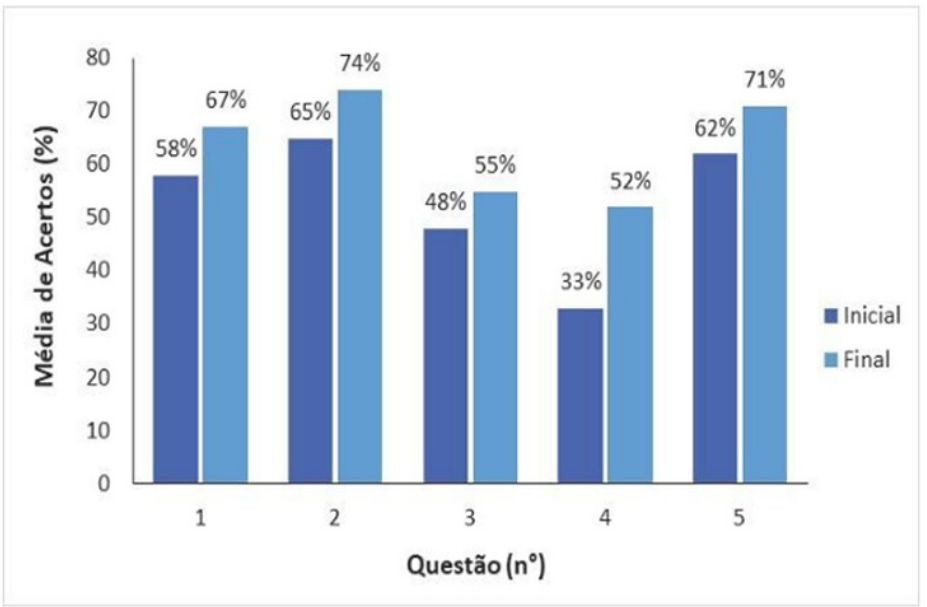

Gráfico 3. Avaliação do rendimento total em Biotecnologia Vegetal

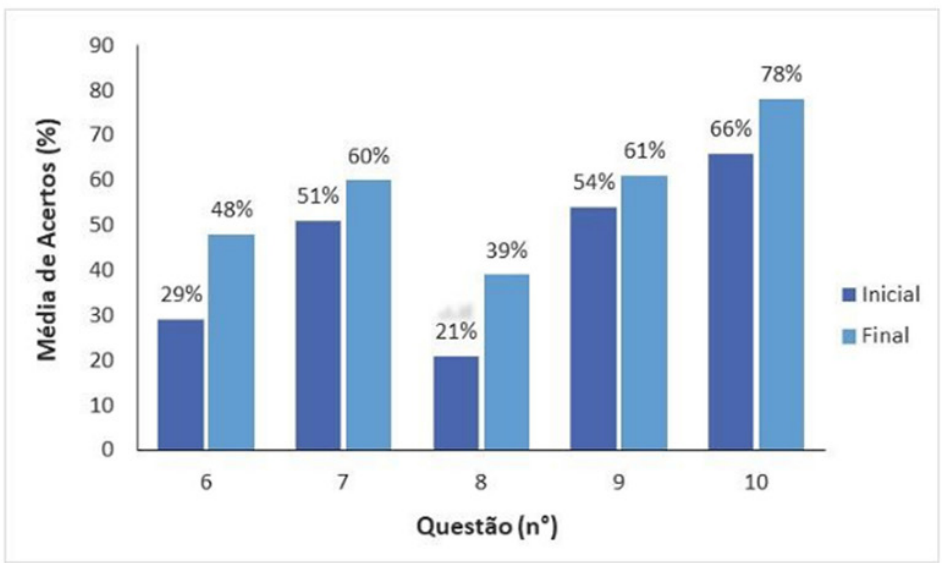


Apesar de pequenas diferenças entre as turmas, o percentual de acertos nas respostas ao questionário, ao final do projeto, tem sido regular ao longo dos anos analisados, indicando grande nivelamento dos alunos do CEJA ao longo do tempo. Por esta razão, o impacto em termos de rendimento dos alunos foi avaliado sobre a totalidade de alunos nos três anos de aplicação. Observando-se o rendimento geral dos alunos nos questionários em Biologia vegetal básica (Gáfico 2) e Biotecnologia Vegetal (Gráfico $3)$, verifica-se que a maior parte dos alunos demonstra desconhecimento dos temas básicos relacionados à biologia e fisiologia, o que dificulta a compreensão de fenômenos biológicos em geral, ressaltando a necessidade do reforço desses conteúdos. Todavia, nos debates realizados após as atividades, a maioria reconhece a importância da biotecnologia vegetal na conservação da biodiversidade vegetal, indicando uma maior compreensão do tema ao final.

Alguns ajustes metodológicos foram introduzidos a cada ano, visando melhorar o desempenho dos alunos de forma geral, mas os resultados mostraram que os poucos alunos que se posicionaram de forma fundamentada, carrearam o melhor desempenho de algumas turmas. Esta variação decorre não só do interesse particular, mas também da diversidade de situações econômicas das famílias dos alunos, o que pode favorecer a aquisição de conhecimentos em alguns casos. Em função desta constatação está sendo avaliada a possibilidade de aplicar o projeto também em outras escolas, localizadas em áreas com perfis e vocações diferentes da região administrativa de Vila Isabel, onde o projeto vem sendo aplicado desde 2012.

Além do impacto da Biotecnologia Vegetal, o projeto privilegiou a organização interdisciplinar do conhecimento básico, uma vez que o reforço proposto em Biologia Vegetal aborda fenômenos de química e física para a compreensão da fisiologia das plantas, diversificando e ampliando os ambientes de aprendizagem (sala de aula, sala de vídeo, laboratório). Assim, os alunos tiveram a oportunidade de conhecer a Biotecnologia Vegetal, através de atividades diferentes (palestras e visita ao laboratório) e passaram por novas experiências de aprendizagem através do contato com jovens profissionais envolvidos com pesquisa, visto que a maioria não cogita a possibilidade de se tornar pesquisador ou cientista no país. Estes resultados estão em acordo com abordagens similares que descrevem o entusiasmo dos alunos com o tema, principalmente pela aproximação com a pesquisa no contexto acadêmico atual. ${ }^{16}$

O projeto também foi avaliado em função da qualificação dos universitários envolvidos em sua aplicação. Foi observado um amadurecimento nos estudantes de Ciências Biológicas que aplicaram as diferentes atividades, vivenciando o universo das salas de aula das escolas participantes. A experiência também foi enriquecedora aos pós-graduandos de mestrado e doutorado, que puderam manter o senso de realidade, muitas vezes camuflado em um período de especialização extrema, com a disponibilidade de um canal importante de discussão e disseminação de conceitos relativos a temas atuais. Nestas tarefas, além de transmitir os conhecimentos técnico-científicos recebidos na Universidade, todos puderam desenvolver a percepção de que muitos fatores podem afetar a capacidade cognitiva dos alunos. 


\section{Considerações Finais}

Considerando o interesse demonstrado pelos alunos nos temas abordados, apesar das dificuldades conceituais, pode-se concluir que a forma dinâmica de apresentar conceitos teóricos e suas aplicações fez uma diferença motivacional. Por essa razão, além do estudo da Biotecnologia Vegetal, o estudo da fisiologia e seus processos de transformação poderiam complementar o conteúdo de ciências, desde o ensino fundamental, de forma que os jovens chegassem ao ensino médio com a noção precisa da importância das plantas na manutenção do equilíbrio ambiental e da ferramenta poderosa representada pela Biotecnologia para a manutenção desse equilíbrio. Assim, a conscientização proposta no projeto, poderia atingir uma parcela muito mais ampla dos alunos que completam o ensino médio, e os resultados poderiam ser perceptíveis mais rapidamente.

Deve-se considerar também a ação multiplicativa dos próprios alunos fora da escola, de forma lenta, mas gradual, pois a aplicação contínua, em novas turmas e escolas, aliada a outros projetos com temática similar, poderiam promover um nível de conscientização cada vez mais abrangente, em relação ao tema.

\section{Contribuições dos autores}

Rachel Fatima Gagliardi - coordenação do projeto e redação do artigo

Cláudia Ribeiro da Silva - professora do CEJA, responsável pelas turmas e cronogramas Bianka de Oliveira Soares - supervisão de alunos de graduação e apresentação de palestras

Renata Garcia - organização das práticas demonstrativas no NBV/UERJ

Jamine de Almeida Pettinelli - supervisão de alunos de graduação e apresentação de palestras

Isabela Brandão de Sousa - supervisão de alunos de graduação e apresentação de palestras

\section{Agradecimentos}

Ao Departamento de Extensão da UERJ pelo apoio, através da concessão de uma bolsa de extensão. Às professoras Liane Peixoto Rocha e Ana Paula Guimarães pelas avaliações preliminares. À Direção do Colégio Estadual João Alfredo, por autorizar a aplicação do projeto nas dependências do estabelecimento, disponibilizando a infraestrutura necessária. À Capes, CNPq e Faperj pelos auxílios concedidos ao longo dos quatro anos de vigência do projeto.

\section{Referências}

1. BRASIL. Ministério do Meio Ambiente. Convenção da Diversidade Biológica. 2000.

2. BRASIL. Ministério da Educação. Parâmetros Curriculares Nacionais (PCN Ensino Médio) - Parte III - Ciências da Natureza, Matemática e suas Tecnologias, 2000.

3. BRASIL. Lei de Diretrizes e Bases da Educação Nacional, Lei no 9394. 1996. 
4. PEDRANCINI, Vanessa Daiana; CORAZZA-NUNES, Maria Júlia; GALUCH, Maria Terezinha Bellanda; MOREIRA, Ana Lúcia Olivo Rosas; RIBEIRO, Alessandra Cláudia. Ensino e aprendizagem de Biologia no ensino médio e a apropriação do saber científico e biotecnológico. Revista Electrónica de Enseñanza de las Ciências, Vigo, v.6, n.2, p.299-309, 2007.

5. CRUZ, Lílian Pereira; JOAQUIM, Walderez Moreira; FURLAN, Marcos Roberto. O estudo de plantas medicinais no ensino fundamental: uma possibilidade para o ensino da Botânica. Thesis, São Paulo, n.15, p.78-92, 2011.

6. SILVA, Juliana Nascimento; GHILARDI-LOPES, Natalia Pirani. Botânica no ensino fundamental: diagnósticos de dificuldades no ensino e da percepção e representação da biodiversidade vegetal por estudantes. Revista Eletrônica de Enseñanza de las Ciencias, Vigo, v.13, n.2, p.115-136, 2014.

7. NOGUEIRA, A.C.O. Cartilha em quadrinhos: um recurso dinâmico para se ensinar botânica. In: Coletânea do 60 Encontro Perspectivas do ensino de Biologia. São Paulo, 1997.

8. SCHELEY, T.R.; SILVA, C.R.P.; CAMPOS, L.M.L. A motivação para aprender biologia: o que revelam alunos do ensino médio. Revista da SBENBIO, n. 7, p.4965-4974, 2014.

9. SILVA, Francilvania Santos Santana; MORAIS, Lelle Jane Oliveira; CUNHA, lane Paula Rego. Dificuldades dos professores de Biologia em ministrar aulas práticas em escolas públicas e privadas do município de imperatriz (MA). Revista UNI, Imperatriz, n.1, p.135-149, 2011.

10. KRASILCHIK, Myrian. Prática de Ensino de Biologia. 6ㅌ. Ed. São Paulo: EDUSP. 2008.

11. MIANI, C.S.; BRANDO, F.R.; CALDEIRA, A.M.A. Tomada de decisões: como futuros professores de Biologia se posicionam em relação à conservação da biodiversidade? In: Congreso Iberoamericano de Ciencia, Tecnología, Innovación y Educación, 937. Buenos Aires, 2014. 13p.

12. BRASIL. Ministério da Educação. Secretaria de Educação Básica. Diretrizes Curriculares Nacionais Gerais da Educação Básica/ Ministério da Educação. Secretaria de Educação Básica. Diretoria de Currículos e Educação Integral. Brasília: MEC, SEB, DICEI, 2013.

13. SOUSA, I.B.; SOARES, B.O.; PETTINELLI, J.A.; GARCIA, R.; SILVA, C.; GAGLIARDI, R.F. Conservação in vitro da biodiversidade vegetal: abordagem no Ensino

Médio. Revista Brasileira de Extensão Universitária (no prelo).

14. WMA. Declaration of Helsinki - Ethical Principles for Medical Research Involving Human Subjects. In: 64th WMA General Assembly, Fortaleza, 2013.

15. DIREITO, Ida Carolina Neves; FIGUEIRÓ, Ronaldo; ALVES, Marcelo Paraíso; OLIVEIRA, Antonio Marcos.; MELLO, Marise Costa; COELHO, Maria Rita; SALLES, João Bosco; VIEIRA, Jéssica Manya; SILVA, Luciana Portal; DOCILE., Tatiana Nascimento; ASSIS, Maria Cristina. Conhecimento Científico em Biotecnologia de estudantes do Ensino Médio de escolas públicas na Zona Oeste do Rio de Janeiro. Revista Práxis, Volta Redonda, n.11, p.115-124, 2014.

16. FAGUNDES, W.A.; PEREIRA, C.M.; CRISOSTIMO, A.L. A aplicação da Biotecnologia no ensino como forma de disseminar Ciência \& Tecnologia. In: 4‥ Congresso Internacional de Educação Pesquisa e Gestão. CIEPG, Ponta Grossa, 2012. 9p 